\title{
Custos no Desdobro de Pinus spp. com Utilização de Modelos de Corte numa Serraria
}

\author{
Alberto António Manhiça ${ }^{1}$, Márcio Pereira da Rocha ${ }^{2}$, \\ Romano Timofeiczyk Junior ${ }^{3}$ \\ 'Área de Tecnologia da Madeira, Centro de Investigação Florestal - CIF, \\ Instituto de Investigação Agrária de Moçambique - IIAM, Maputo, Moçambique \\ ${ }^{2}$ Departamento de Engenharia e Tecnologia Florestal, Universidade Federal do Paraná - UFPR, Curitiba/PR, Brasil \\ ${ }^{3}$ Departamento de Economia Rural e Extensão, Universidade Federal do Paraná - UFPR, Curitiba/PR, Brasil
}

\begin{abstract}
RESUMO
Este trabalho teve o objetivo de analisar o custo de produção de madeira serrada nos sistemas de desdobro aleatório e programado, para diferentes classes diamétricas. Foram selecionadas 80 toras de Pinus spp. com diâmetros que variaram de 24 a $33 \mathrm{~cm}$, formando quatro classes diamétricas com 20 toras por classe. Em cada classe, as toras foram separadas em dois lotes com dez unidades, sendo que o primeiro lote foi submetido ao desdobro aleatório e o segundo lote foi submetido ao desdobro programado. As análises de custos revelaram que, no sistema de desdobro programado, houve redução nos valores obtidos.
\end{abstract}

Palavras-chave: desdobro de toras, otimização, custos.

\section{Cost of Pinus spp. Log Processing Using Cutting Templates in a Sawmill}

\begin{abstract}
This research aimed to analyze the production cost of lumber using randomized and programmed cutting systems for different diameter classes. We selected $80 \operatorname{logs}$ of Pinus spp with diameters ranging from 24 to $33 \mathrm{~cm}$, divided in four diameter classes, with 20 logs per class. In each class, the logs were separated in two lots of 10 units - the first batch was subjected to randomized cutting and the second batch was submitted to programmed cutting. The cost analysis showed that there was reduction in values when the programmed cutting system was used.
\end{abstract}

Keywords: cutting of logs, optimization, costs.

\section{INTRODUÇÃO}

O pinus constitui uma das essências florestais mais utilizadas no Brasil, na indústria de madeira processada mecanicamente. A Região Sul do País concentra a maior parte de suas florestas, sendo os Estados do Paraná e de Santa Catarina detentores da maior área plantada com o pinus (ABRAF, 2012). As perspectivas de crescimento no consumo de toras de Pinus spp. no Brasil para uso industrial têm se mostrado promissoras.

É importante que o estabelecimento de novos plantios para fazer face à demanda por madeira de reflorestamento esteja associado ao desenvolvimento 
de novas tecnologias, visando a melhorar os níveis de aproveitamento da matéria-prima e assegurar o suprimento da indústria ao longo do tempo. Algumas serrarias adotam novos procedimentos técnicos no processamento da madeira, que visam a reduzir os custos de produção e incrementar valor ao produto final, para manter a competitividade no mercado.

O conhecimento destes custos é fundamental para o planejamento e a administração, bem como de extrema importância para se conhecer a eficiência econômica da empresa. Para as empresas garantirem a sua inserção no mercado e manterem a sua competitividade, é imprescindível que disponham de um sistema de gestão de custos que consiga medir e alocar os custos aos produtos de forma mais precisa possível, sendo necessário calcular os custos unitários ou custos médios (Wernke, 2005).

De acordo com Pyndyck e Rubinfeld (2009), os custos médios podem servir de base na análise de situações de lucratividade da empresa. Uma empresa maximiza o lucro quando a receita marginal for igual ao custo marginal. No entanto, em um mercado de concorrência perfeita, o lucro máximo dependerá da diferença entre o preço do produto, que é a receita marginal nesta estrutura do mercado, e o custo total médio do mesmo produto.

Assim, é possível dispor de uma metodologia de desdobro de toras que envolva a classificação destas e o estabelecimento de modelos de corte para diferentes classes diamétricas, empregando um programa de computador que resulte na redução de custos. No caso específico de serrarias que desdobram toras de pinus, os aspectos ligados à melhoria de rendimento tornam-se importantes, pois se trata de matériaprima de pequenas dimensões e baixa qualidade (Vianna Neto, 1984).

Entretanto, na Região Sul do Brasil, é comum encontrar várias serrarias pequenas processando a madeira de pinus com equipamentos obsoletos. A operação de desdobro é dependente da experiência do operador da máquina principal na visualização de todas para a tomada de decisão, visando à retirada de peças de madeira para atender ao objetivo da empresa. Essa atitude, na maioria das vezes, resulta em níveis relativamente baixos de rendimento em madeira serrada, acarretando um aproveitamento inadequado da matéria-prima, além de ocorrer maior consumo de madeira em toras para alcançar a meta de produção da empresa.

Atualmente, existem programas capazes de avaliar automaticamente as características da tora, permitindo a visualização das condições programadas de desdobro. Estes programas estão associados a outros equipamentos, como scanners que fazem a varredura do perfil da tora providenciando informações no formato tridimensional, as quais são visualizadas pelo operador no computador.

Assim, os programas fornecem o modelo de corte pelo qual será desdobrada a tora, os produtos a serem obtidos e o respectivo rendimento estimado, ao passo que o desdobro convencional. $\mathrm{O}$ uso desses programas contribui para o aumento da produtividade na serraria. Neste contexto, com esta pesquisa, pretendeu-se avaliar uma metodologia de desdobro de toras que envolveu a classificação destas e o estabelecimento de modelos de corte para diferentes classes diamétricas, a partir de um programa de computador visando a otimização e redução de custos no desdobro de toras.

\section{MATERIAL E MÉTODOS}

\subsection{Local do experimento e descrição da serraria}

O trabalho foi realizado em uma serraria de uma empresa localizada no município de Campina Grande do Sul, no Estado do Paraná. A empresa é composta por uma serraria e uma unidade de beneficiamento da madeira, dedicando-se à manufatura de produtos de madeira com maior valor agregado, como caixilhos, rodapés, painéis EGP (Edge Glued Panel) e outros produtos para construção civil. A serraria é de pequeno porte, uma vez que a sua produção de madeira serrada é menor do que $500 \mathrm{~m}^{3} / \mathrm{mês}$, de acordo com Vital (2008).

Para as operações de desdobro de toras, a serraria dispõe de uma serra de fita simples acoplada ao carro porta-tora, que é acionado pelo operador a partir do painel de controle; uma serra de fita horizontal de dois cabeçotes para resserragem, e uma serra circular múltipla de um eixo com três discos, dos quais, um é móvel. A serra circular múltipla foi usada para o refilamento. O lay-out que ilustra a disposição das 
máquinas é apresentado na Figura 1. A serraria apresenta baixo nível de automação, sendo que a operação dos equipamentos é dependente, em parte, da mão de obra. Sendo assim, a serraria operava com cinco funcionários.

\subsection{Espécie utilizada}

A espécie utilizada, neste trabalho, foi Pinus elliottii. A serraria recebia no seu pátio toras com diâmetros de $24 \mathrm{~cm}$ a $33 \mathrm{~cm}$, e com comprimento de $2,55 \mathrm{~m}$ a 2,60 $\mathrm{m}$. A mesma tinha um consumo médio mensal de 1200 st de toras, o equivalente a $827,59 \mathrm{~m}^{3}$, considerando-se o fator de empilhamento de 1,45 para toras de $24 \mathrm{~cm}$ a $33 \mathrm{~cm}$ de diâmetro.

\subsection{Seleção de toras e classes diamétricas utilizadas}

No pátio de toras, foram selecionadas 80 toras agrupadas em quatro classes diamétricas, com base no diâmetro médio ou se o diâmetro da ponta fina fosse igual ou superior ao limite inferior da classe considerada, tendo como resultado 20 toras por

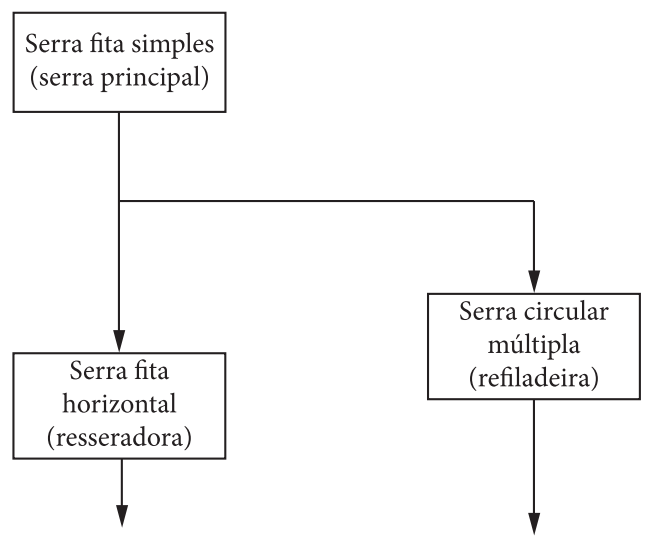

Figura 1. Lay-out da serraria ilustrando a disposição das máquinas.

Figure 1. Sawmill lay-out illustruded in the machines arrangement. classe diamétrica (Tabela 1). As toras selecionadas receberam um número de identificação e foram pintadas na ponta fina para facilitar o controle no rastreamento desde o pátio até o final da linha de produção.

\subsection{Sistemas de desdobro usados}

As toras de cada classe diamétrica foram separadas em dois lotes com dez unidades, submetidas a duas metodologias de desdobro: aleatório e programado. O desdobro programado deu-se de acordo com modelo de corte pré-estabelecido, com base no programa simulador MaxiTora para a classe diamétrica correspondente.

As toras foram desdobradas nos dois sistemas para obter peças de madeira serrada nas segintes dimensões: $42 \mathrm{~mm} \times 80 \mathrm{~mm} ; 42 \mathrm{~mm} \times 120 \mathrm{~mm}$; $42 \mathrm{~mm} \times 150 \mathrm{~mm} ; 42 \mathrm{~mm} \times 180 \mathrm{~mm} ; 22 \mathrm{~mm} \times$ $80 \mathrm{~mm}$, e $22 \mathrm{~mm} \times 160 \mathrm{~mm}$.

No sistema aleatório, as toras foram desdobradas de acordo com os critérios da empresa, sem que houvesse alguma intervenção nas operações. $\mathrm{O}$ sistema de desdobro predominantemente utilizado foi do tipo tangencial sucessivo, resultando em várias peças com faces planas, mas que requeriam o refilamento.

No sistema programado, foi usado o diâmetro médio da classe para gerar o modelo de corte correspondente. Cada tora foi desdobrada de acordo com o modelo de corte da classe diamétrica correspondente (Figura 2). As toras passavam pela serra principal definindo-se as espessuras finais e, em seguida, passavam pela refiladeira, proporcionando às peças a largura final.

\subsection{Custos de produção}

Os dados para esta pesquisa foram fornecidos pela empresa. Para a apuração dos custos, foram

Tabela 1. Número de toras selecionadas por classe diamétrica.

Tabela 1. Number of logs selected by diametric class.

\begin{tabular}{|c|c|c|c|}
\hline N.o & Classe diamétrica (cm) & N. ${ }^{\circ}$ de toras selecionadas & Comprimento (m) \\
\hline 1 & $24,0-26,0$ & 20 & $2,55-2,60$ \\
\hline 2 & $26,1-28,0$ & 20 & $2,55-2,60$ \\
\hline 3 & $28,1-30,0$ & 20 & $2,55-2,60$ \\
\hline 4 & $30,1-33,0$ & 20 & $2,55-2,60$ \\
\hline Total & & 80 & \\
\hline
\end{tabular}




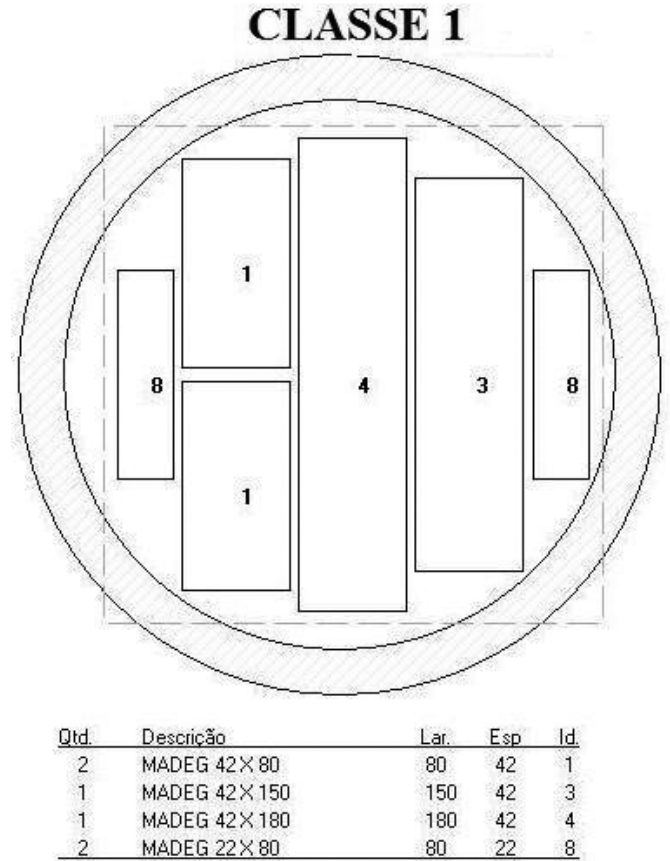

Diametro: 2500 Percentual de Aproveitamento: $49,10 \%$

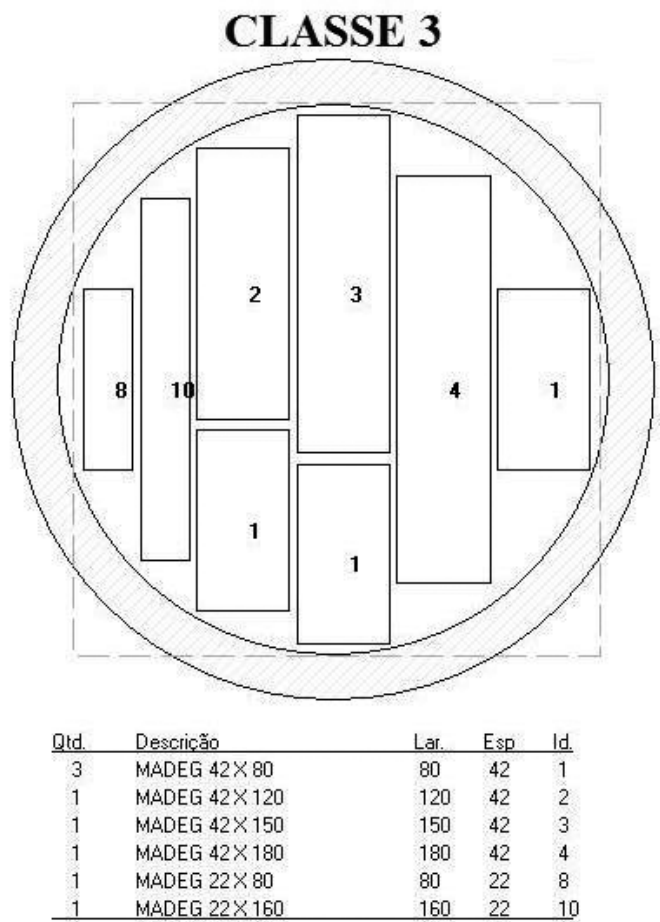

Diametro: 2910 Percentual de Aproveitamento: $51,51 \%$

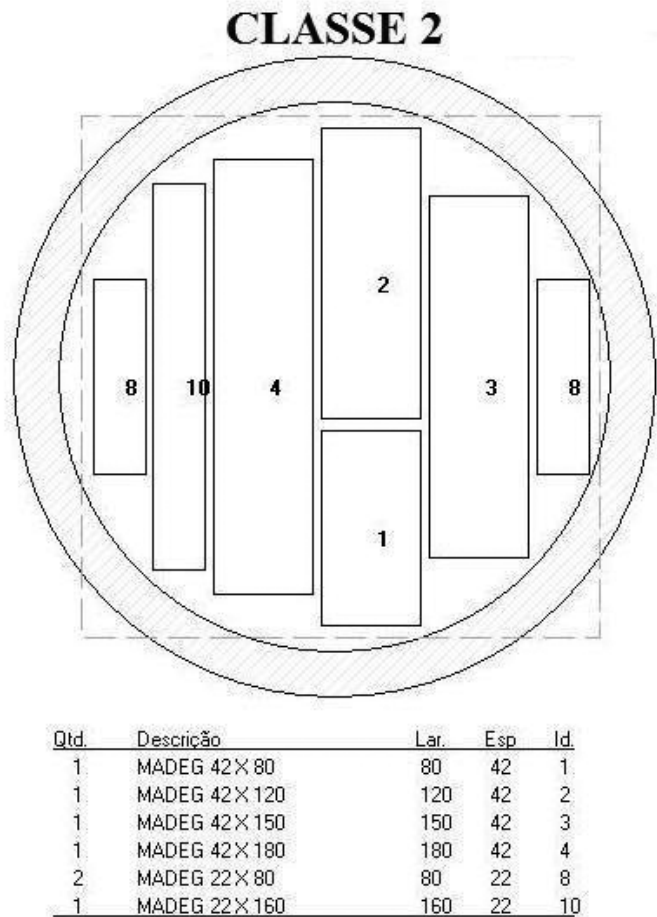

Diametro: 2710 Percentual de Aproveitamento: $50,80 \%$

\section{CLASSE 4}

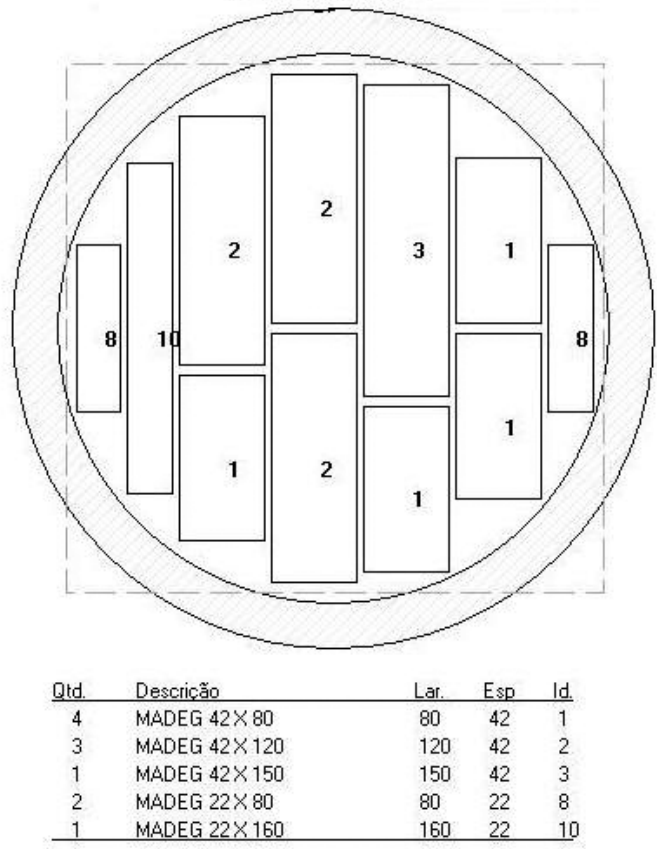

Diametro: 3160 Percentual de Aproveitamento: $53,43 \%$

Figura 2. Modelos de corte estabelecidos para quatro classes diamétricas.

Figure 2. Cutting models set for four diameter classes. 
considerados os gastos decorrentes do processo de desdobro de toras para a obtenção de madeira serrada. Tais gastos foram classificados como custos fixos e variáveis, para, posteriormente, se calcularem os custos totais, custos fixos médios, custos variáveis médios e custos totais médios.

\subsubsection{Custos fixos}

Os custos fixos incluíram gastos referentes a salário da mão de obra direta; encargos sociais; depreciação de máquinas e equipamentos; remuneração do capital próprio; despesas administrativas, e ferramentas.

O valor relativo ao salário da mão de obra direta foi obtido a partir da folha de pagamento. Os encargos sociais, associados ao INSS e ao FGTS, foram obtidos pela aplicação do percentual de $17,5 \%$ ao salário de mão de obra, obtido da folha de pagamento.

A depreciação foi definida como sendo a diminuição do valor dos bens ativos, resultante do desgaste por uso, ação da natureza ou por obsoletismo (Hildebrand, 1995). A metodologia de cálculo usada para a obtenção da depreciação linear é representada pela Equação 1, de acordo com Timofeiczyk Junior (2004):

$$
D e=(V a-V r) / V u
$$

em que: $\mathrm{De}=$ Depreciação, em R $\$$ /ano; Va $=$ Valor de aquisição, em R\$; Vr = Valor residual, em R\$; $\mathrm{Vu}=$ Vida útil, em meses.

A depreciação foi calculada em relação aos seguintes equipamentos e máquinas: serra de fita simples; esteira de alimentação de toras; carro pneumático; esteiras transportadoras diversas; serra circular múltipla; empilhadeira; infraestrutura, e móveis.

A remuneração do capital constitui os juros mínimos recebidos pelo capital empregado na compra ou na aquisição de um bem (Mendes \& Hildebrand, 1997). A remuneração do capital próprio foi obtida a partir do percentual de $0,65 \%$ sobre o valor de aquisição de máquinas e equipamentos de serraria. $\mathrm{O}$ valor resultante, de acordo com a empresa, constitui a poupança mensal para eventualmente ser usada na aquisição de novas máquinas ou equipamentos.
Os valores referentes às despesas administrativas e aos gastos na aquisição de ferramentas foram fornecidos pela empresa.

\subsubsection{Custos variáveis}

Os custos variáveis incluíram gastos referentes à aquisição da matéria-prima (toras), do combustível, da energia elétrica e da água, além dos gastos com a manutenção em geral.

$\mathrm{O}$ custo referente à aquisição da matéria-prima (toras) foi calculado a partir da Equação 2:

\section{$M T=\operatorname{Pr} \times V t$}

em que: $\mathrm{MT}=$ Custo da Matéria-Prima (Toras), em $\mathrm{R} \$ \mathrm{Pr}=$ Preço por $\mathrm{m}^{3}$ de toras; $\mathrm{Vt}=$ Volume de toras adquiridas, em $\mathrm{m}^{3}$ por mês.

Os valores referentes a combustível, energia elétrica e água consumida foram fornecidos pela empresa. Os custos de manutenção incluíram também a aquisição de lubrificantes, pneus e outros acessórios.

\subsubsection{Custo total de produção}

O custo total foi obtido a partir do somatório dos custos fixo e variável, de acordo com a Equação 3:

$C T=\sum C F T+\sum C V T$

em que: $\mathrm{CT}=$ Custo Total, em R\$; CFT = Somatório dos Custos Fixos, em R\$; CVT = Somatório dos Custos Variáveis, em R\$.

\subsection{Custos unitários de produção}

O custo fixo médio foi calculado a partir da Equação 4:

$$
C F m=\frac{C F T o t}{V m s}
$$

em que: $\mathrm{CFm}=$ Custo Fixo médio, em $\mathrm{R} \$ / \mathrm{m}^{3}$; $\mathrm{CFT}=$ Custo Fixo Total, em R $\$$; Vms = Volume total de madeira serrada produzida por mês, em $\mathrm{m}^{3}$.

O custo variável médio foi calculado a partir da Equação 5:

$C V m=\frac{C V T}{V m s}$ 
em que: $\mathrm{CVm}=$ Custo Variável médio, em $\mathrm{R} \$ / \mathrm{m}^{3}$; CVT = Custo Variável Total, em R\$; Vms = Volume total de madeira serrada produzida por mês, $\mathrm{em}^{3}$.

O custo total médio do produto foi calculado a partir da Equação 6:

$$
C T m=\frac{C T}{V m s}
$$

em que: $\mathrm{CTm}=$ Custo Total médio, em $\mathrm{R} \$ / \mathrm{m}^{3}$; $\mathrm{CT}=$ Custo Total, em R\$; Vms = Volume total de madeira serrada produzida por mês, $\mathrm{em}^{3}$.

O volume de madeira serrada produzida por mês foi estimado para cada sistema de desdobro (aleatório e programado), a partir do rendimento conseguido pela serraria, usando cada sistema e tendo sido considerado o consumo médio de toras por mês.

\section{RESULTADOS E DISCUSSÃO}

\subsection{Desdobro aleatório}

Os custos fixos e variáveis da serraria são apresentados na Tabela 2, e constituíram os custos de produção pelo desdobro aleatório. O custo total alcançou o valor de $\mathrm{R} \$ 106.780,07$ por mês e representou o custo de todos os recursos fixos e variáveis usados para gerar a produção. Desse valor, $15,69 \%$ são devidos à utilização de recursos fixos, e $84,31 \%$ resultam da utilização de recursos variáveis. Os recursos variáveis tiveram um impacto significativo sobre os custos totais de produção de madeira.

Analisando-se a Tabela 3, pode-se observar que a serraria se depara com um custo fixo total de $\mathrm{R} \$ 16.758,78$ por mês. A depreciação de máquinas e equipamentos, a mão de obra direta e as despesas administrativas foram responsáveis por 30,01\%, $28,66 \%$ e $20,88 \%$ respectivamente, do custo fixo total. Os mesmos elementos representam apenas 4,49\%, $4,71 \%$ e $3,28 \%$, respectivamente, do custo total.

Nos custos variáveis, o destaque vai para a aquisição de toras, constituindo esta o elemento de custo de grande importância, em razão do impacto ocasionado nos custos de produção da serraria. Analisando-se a Tabela 4, pode-se observar que a matéria-prima (toras) representou 93,31\% do custo variável total mensal e foi responsável por $78,67 \%$ do custo total. Berger et al. (2002) avaliaram economicamente a implantação de uma serraria de grande porte no Estado do Acre e determinaram o custo variável total mensal. Os autores verificaram que a aquisição de matéria-prima (toras) como elemento do custo variável tinha um grande impacto sobre os custos de produção na serraria, respondendo por $62,50 \%$ do custo total.

Tabela 2. Custo fixo total, custo variável total e custo total da serraria com desdobro aleatório. Table 2. Total fixed cost, variable cost and total cost of the mill to unfold random.

\begin{tabular}{|c|c|c|}
\hline Itens do custo & R\$ por mês & $\%$ do Custo Total \\
\hline Custo fixo total & $16.758,78$ & 15,69 \\
\hline Custo variável total & $90.021,29$ & 84,31 \\
\hline Custo Total & $106.780,07$ & 100,00 \\
\hline
\end{tabular}

Tabela 3. Custos fixos totais da serraria no desdobro aleatório.

Table 3. Total fixed costs in the sawmill unfold random.

\begin{tabular}{lccc}
\multicolumn{1}{c}{ Itens do custo fixo } & R\$ por mês & \% do Custo Fixo & \% do Custo Total \\
\hline Mão de obra direta & $4.802,65$ & 28,66 & 4,49 \\
\hline Encargos sociais & 840,46 & 5,02 & 0,79 \\
\hline Depreciação de máquinas e equipamentos & $5.029,17$ & 30,01 & 4,71 \\
Remuneração do capital próprio & $2.307,50$ & 13,77 & 2,16 \\
Despesas administrativas & $3.500,00$ & 20,88 & 3,28 \\
\hline Ferramentas & 279,00 & 1,66 & 0,26 \\
\hline Custo Fixo Total & $16.758,78$ & 100,00 & 15,69 \\
\hline
\end{tabular}




\subsection{Desdobro programado}

O custo fixo total, o custo variável total e o custo total calculados para o desdobro aleatório foram os mesmos para o desdobro programado. Entretanto, os custos médios obtidos foram diferentes para os dois sistemas de desdobro. Na Tabela 5, é apresentado o comparativo dos componentes de custos fixos médios entre os sistemas de desdobro aleatório e programado.

A serraria atingiu, pelo desdobro aleatório, a produção mensal de 405,60 $\mathrm{m}^{3}$ de madeira serrada. No entanto, a partir do desdobro programado, a serraria atingiu a produção mensal de $431,50 \mathrm{~m}^{3}$ de madeira serrada, correspondendo a um aumento de 6,39\% em relação ao desdobro aleatório. Note-se que foi usada a mesma quantidade de toras para os dois sistemas de desdobro.

Analisando-se a Tabela 5, pode ser observado que, com o sistema de desdobro programado, houve diminuição do custo médio em todos os componentes do custo fixo, ocasionando a redução do custo fixo médio de $\mathrm{R} \$ 41,32 / \mathrm{m}^{3}$ para $\mathrm{R} \$ 38,84 /$ $\mathrm{m}^{3}$ de madeira serrada produzida. A redução do custo fixo médio foi registrada em função de se ter aumentado o volume de produção mensal de madeira serrada, em virtude da programação de desdobro de toras. Mendes (1998) menciona que, uma vez que o custo fixo total permanece constante em curto prazo, o aumento da produção proporciona a redução do custo fixo médio.

Na Tabela 6, é apresentado o comparativo dos componentes de custos variáveis médios entre os sistemas de desdobro aleatório e programado. Pode-se observar que ocorreu a redução do custo médio em todos os componentes do custo variável, ocasionando a diminuição do custo variável médio de $R \$ 221,95 / \mathrm{m}^{3}$ para $\mathrm{R} \$ 208,63 / \mathrm{m}^{3}$ em razão do aumento do volume de produção de madeira serrada, com a programação do desdobro de toras.

A matéria-prima (toras) foi o elemento de custo variável que criou um impacto significativo na estrutura de custos da serraria, representando $78,67 \%$ do custo total. No entanto, na Tabela 6, pode ser observado que o custo médio da matériaprima reduziu de $\mathrm{R} \$ 207,10 / \mathrm{m}^{3}$ para $\mathrm{R} \$ 194,67 /$ $\mathrm{m}^{3}$, sendo da ordem de $\mathrm{R} \$ 12,43 / \mathrm{m}^{3}$ por mês e $\mathrm{R} \$$ $149,16 / \mathrm{m}^{3}$ ao ano, com a programação de desdobro de toras. Assim, uma vez que foi utilizado o mesmo volume de matéria-prima para os dois sistemas de

Tabela 4. Custos variáveis totais da serraria no desdobro aleatório.

Table 4. Total variable costs sawmill unfold in random.

\begin{tabular}{lccc}
\multicolumn{1}{c}{ Itens do custo variável } & R\$ por mês & \% do Custo Variável & \% do Custo Total \\
\hline Matéria-prima (Toras) & $84.000,39$ & 93,31 & 78,67 \\
\hline Combustível & 702,00 & 0,78 & 0,66 \\
Energia elétrica & $3.417,87$ & 3,80 & 3,20 \\
\hline Água & 11,88 & 0,013 & 0,011 \\
$\begin{array}{l}\text { Manutenção em geral (inclui lubrificantes, } \\
\text { pneus, etc.) }\end{array}$ & $1.889,15$ & 2,10 & 1,77 \\
Custo Variável Total & $90.021,29$ & 100 & 84,31 \\
\hline
\end{tabular}

Tabela 5. Comparação de componentes de custo fixo médio entre os desdobros aleatório e programado. Table 5. Comparison of average fixed cost components unfold between the random and scheduled.

\begin{tabular}{|c|c|c|c|}
\hline \multirow{2}{*}{ Item de custo fixo } & \multicolumn{2}{|c|}{ Custo médio $\left(\mathbf{R} \$ / \mathrm{m}^{3}\right)$} & \multirow{2}{*}{ Diferencial $\left(\mathbf{R} \$ / \mathrm{m}^{3}\right)$} \\
\hline & Desdobro aleatório & Desdobro programado & \\
\hline Mão de obra direta & 11,84 & 11,13 & 0,71 \\
\hline Encargos sociais & 2,07 & 1,95 & 0,12 \\
\hline Depreciação de máquinas e equipamentos & 12,40 & 11,66 & 0,41 \\
\hline Remuneração do capital próprio & 5,69 & 5,35 & 0,34 \\
\hline Despesas administrativas & 8,63 & 8,11 & 0,52 \\
\hline Ferramentas & 0,69 & 0,64 & 0,04 \\
\hline Total & 41,32 & 38,84 & 2,48 \\
\hline
\end{tabular}


Tabela 6. Comparação de componentes de custo variável médio entre os desdobros aleatório e programado.

Table 6. Comparison of average variable cost components unfold between the random and scheduled.

\begin{tabular}{|c|c|c|c|}
\hline \multirow{2}{*}{ Item de custo variável } & \multicolumn{2}{|c|}{ Custo médio $\left(\mathrm{R} \$ / \mathrm{m}^{3}\right)$} & \multirow{2}{*}{$\begin{array}{c}\text { Diferencial } \\
\left(\mathbf{R} \$ / \mathbf{m}^{3}\right)\end{array}$} \\
\hline & Desdobro aleatório & Desdobro programado & \\
\hline Matéria-prima (Toras) & 207,10 & 194,67 & 12,43 \\
\hline Combustível & 1,73 & 1,63 & 0,10 \\
\hline Energia elétrica & 8,43 & 7,92 & 0,51 \\
\hline Água & 0,029 & 0,028 & 0,001 \\
\hline $\begin{array}{l}\text { Manutenção em geral } \\
\text { (inclui lubrificantes, pneus, etc.) }\end{array}$ & 4,66 & 4,38 & 0,28 \\
\hline Total & 221,95 & 208,63 & 13,32 \\
\hline
\end{tabular}

Tabela 7. Comparação do custo total médio entre os desdobros aleatório e programado nas classes diamétricas. Table 7. Comparison of average total cost between the random and programmed unfold in diameter classes.

\begin{tabular}{lccc}
\multirow{2}{*}{ Classe diamétrica } & \multicolumn{2}{c}{ Custo total médio $\left(\mathbf{R} \mathbf{\$} / \mathbf{m}^{\mathbf{3}}\right)$} & Diferencial $\left(\mathbf{R} \mathbf{\$} / \mathbf{m}^{\mathbf{3}}\right)$ \\
\cline { 2 - 3 } 1 & Desdobro aleatório & Desdobro programado & 28,57 \\
2 & 286,98 & 258,41 & 18,13 \\
3 & 266,97 & 248,84 & 6,28 \\
4 & 256,62 & 250,34 & 12,37 \\
Média & 245,90 & 233,53 & 15,80 \\
\hline
\end{tabular}

desdobro e que, com a programação do desdobro de toras, a produção de madeira serrada aumentou em 6,39\% em relação ao desdobro aleatório, a serraria poderia economizar por mês, na utilização de toras, $\mathrm{R} \$ 12,43 / \mathrm{m}^{3}$ de madeira serrada produzida ou $\mathrm{R} \$ 149,16 / \mathrm{m}^{3}$ ao ano. Os outros componentes de custo variável, como o combustível, a energia elétrica, a água e a manutenção, apresentaram um impacto menor no custo total como recursos variáveis utilizados na produção, quando comparados às toras, representando apenas 5,64\%.

$\mathrm{Na}$ Tabela 7, é apresentado o comparativo de custo total médio alcançado nos sistemas de desdobro aleatório e programado, em diferentes classes diamétricas.

De acordo com a Tabela 7, o custo total médio reduziu-se no sistema de desdobro aleatório assim como no sistema de desdobro programado entre as classes diamétricas, uma vez que houve aumento da produção de madeira serrada em função da classe diamétrica estudada. No entanto, no nível de todas as classes diamétricas, também ocorreu a redução do custo total médio em virtude do sistema de desdobro programado, uma vez que, por este sistema de desdobro, houve aumento da produção de madeira serrada. Analisando-se os valores absolutos de custos na Tabela 7 , observa-se que, nas classes diamétricas 1,2 e 4, evidencia-se que a programação de desdobro de toras permitiu a redução dos custos totais médios.

No geral, o custo total médio da serraria reduziu de $R \$ 263,26 / \mathrm{m}^{3}$ para $\mathrm{R} \$ 247,46 / \mathrm{m}^{3}$, sendo da ordem de $\mathrm{R} \$ 15,80 / \mathrm{m}^{3}$ por mês e $\mathrm{R} \$ 189,60 / \mathrm{m}^{3}$ ao ano. Assim, a serraria, trabalhando com o sistema de desdobro programado, poderia economizar na utilização dos recursos fixos e variáveis, por mês, $\mathrm{R} \$ 15,80 / \mathrm{m}^{3}$ de madeira serrada produzida ou R\$ $189,60 / \mathrm{m}^{3}$ ao ano. No valor mensal ou anual a ser economizado, há maior participação da matériaprima (toras), em 78,67\%, significando que é um recurso de maior importância em função do impacto causado na estrutura de custos da serraria.

Ressalta-se que a serraria pode conseguir economizar mais do que os valores mensal e anual estimados, se fizer um treinamento dos operadores das máquinas no sentido de melhorar o rendimento no desdobro programado, aproveitando melhor as toras, uma vez que, neste sistema de desdobro, o erro dos operadores afetou o rendimento. 


\section{CONCLUSÕES E RECOMENDAÇÕES}

De acordo com os resultados obtidos, concluiuse que:

- A depreciação de máquinas e equipamentos, e a mão de obra foram os elementos com maior participação nos custos fixos;

- A matéria-prima (toras) apresentou a maior participação nos custos variáveis e foi o elemento que mais onerou a produção de madeira serrada;

- O custo médio da matéria-prima (toras) diminuiu com a programação de desdobro de toras; e

- O sistema de desdobro programado permitiu reduzir os custos totais médios de produção.

\section{STATUS DA SUBMISSÃO}

Recebido: 28/02/2012

Aceito: 30/01/2013

Publicado: 30/09/2013

\section{AUTOR(ES) PARA CORRESPONDÊNCIA}

\section{Alberto António Manhiça}

Área de Tecnologia da Madeira, Centro de Investigação Florestal - CIF, Instituto de Investigação Agrária de Moçambique - IIAM, Maputo, Moçambique

e-mail: albertomanhica@yahoo.com.br

\section{Márcio Pereira da Rocha}

Departamento de Engenharia e Tecnologia

Florestal, Universidade Federal do

Paraná - UFPR, Curitiba/PR, Brasil

e-mail: mprocha@ufpr.br

\section{Romano Timofeiczyk Junior}

Departamento de Economia Rural e Extensão, Universidade Federal do Paraná - UFPR,

Curitiba/PR, Brasil

e-mail: romano@ufpr.br

\section{REFERENNCIAS}

Associação Brasileira de Produtores de Florestas Plantadas - ABRAF. Anuário estatístico 2012, ano base 2011. ABRAF; 2012. [cited 2013 Jan. 30]. Available from: http://www.abraflor.org.br/.

Berger R, Timofeiczyk Junior R, Lacowicz GP, Brasil AA. Análise econômica da industrialização primária da madeira na região amazônica. Floresta $e$ Ambiente 2002; 9(1): 9-17.

Hildebrand E. Sistema de apropriação e análise de custos para a empresa florestal [dissertação]. Curitiba: Universidade Federal do Paraná; 1995.

Mendes JTG. Economia Agrícola - Princípios Básicos e Aplicações. 2. ed. Curitiba: ZNT ltda.; 1998.

Mendes JB, Hildebrand E. Procedimentos para a concepção de um sistema de custos florestais. Curitiba: Fupef - Silviconsult Engenharia; 1997. p. 1-26. PMid:9485864.

Pyndyck RS, Rubinfeld DL. Microeconomia. 7. ed. São Paulo: Pearson Education do Brasil; 2009. 647 p.

Timofeiczyk Junior R. Análise econômica do manejo de baixo impacto em florestas tropicais- um estudo de caso [tese]. Curitiba: Universidade Federal do Paraná; 2004.

Vianna Neto JA. Considerações básicas sobre o desdobro de Pinus spp. Silvicultura 1984; 9(34): 15-19.

Vital BR. Planejamento e operação de serrarias. Viçosa: UFV; 2008. $211 \mathrm{p}$.

Wernke R. Análise de custos e preços de venda: ênfase em aplicações e casos nacionais. São Paulo: Saraiva; 2005. 201 p. 